\title{
REESTRUTURAÇÃO PRODUTIVA E SAÚDE NO SETOR METALÚRGICO: a percepção das trabalhadoras
}

\author{
Angela Maria Carneiro Araújo* \\ Eleonora Menicucci de Oliveira**
}

Resumo: Este artigo discute a nova divisão sexual do trabalho que resulta do processo de reestruturação produtiva na indústria metalmecânica, enfatizando seus impactos sobre as condições de trabalho e de saúde das mulheres trabalhadoras. A pesquisa de natureza qualitativa, que foi realizada em plantas de diferentes tamanhos nos setores de autopeças e eletroeletrônico, no ABC paulista e em Campinas, examinou as novas formas do trabalho feminino como resultado da introdução de novas práticas gerenciais e de inovações tecnológicas. Foram também investigadas as percepções das trabalhadoras sobre as mudanças no seu trabalho e nas suas condições de saúde, com o propósito de compreender a relação entre novas formas de organização do processo de trabalho e o aprofundamento do sofrimento psicofísico no trabalho. Concluiu-se que o processo de reestruturação das empresas estudadas tem um claro bias de gênero na medida em que os lugares ocupados pelas mulheres na nova divisão do trabalho contribuem para aumentar a deterioração das suas condições de trabalho. Nas fábricas pesquisadas as trabalhadoras estão mais concentradas nos postos com salários menores, sob condições de trabalho ruins e sem proteção contra os riscos derivados das atividades desempenhadas. $\mathrm{O}$ artigo mostra que há uma nítida relação entre as mudanças nas condições de trabalho das mulheres e o crescimento de problemas de saúde e de doenças ocupacionais (como as LER e o estresse, entre outras).

\footnotetext{
Departamento de Ciência Política da UNICAMP. araujo@unicamp.br

** Departamento de Medicina Preventiva da UNIFESP. leomenicucci@uol.com.br Artigo recebido em 5 abr. 2005 e aprovado em 12 dez. 2005.
} 
Palavras-chave: mulher, divisão sexual do trabalho, setor metalúrgico, reestruturação produtiva, saúde.

\section{Introdução}

É notável a reduzida presença da dimensão de gênero nos estudos sobre a reestruturação produtiva em geral (Abreu, 1993; Abramo, 1998) e sobre os processos de inovação tecnológica e gerencial ocorridos no setor metal-mecânico em particular, bem como sobre seus impactos na saúde da mulher trabalhadora. No entanto, neste setor, considerado majoritariamente masculino, ocorreu, nos últimos 15 anos, um expressivo crescimento da mão-de-obra feminina que, na região de Campinas, passou de cerca de 12,8\%, em 1986, para cerca de 15,9 \%, em 2000 (Araújo, Gitahy, Cunha \& Rachid, 2002). Além disto, em alguns dos segmentos deste ramo industrial, como é o caso dos setores de auto-peças e eletroeletrônico, a porcentagem de mulheres envolvidas na produção chega, em muitas empresas, a ser de $40 \%$ a $60 \%$. Algumas autoras mostram que as inovações tecnológicas e organizacionais trouxeram novas oportunidades de emprego para a mão-de-obra feminina, inclusive em postos anteriormente ocupados principalmente por homens (Hirata, 1998; Posthuma \& Lombardi, 1996). No entanto, salientam que esta incorporação do trabalho feminino aumentou, em parte, em virtude de um novo critério da política de contratação das empresas que se orientam pela redução de custos. $\mathrm{O}$ emprego de mulheres representou para as empresas, nos setores considerados neste estudo, uma desqualificação dos postos por elas ocupados, "justificando salários rebaixados e a conseqüente desvalorização do emprego" (Hirata, 1998, p. 11-12).

Na última década, a reestruturação do setor metal-mecânico teve como característica importante a crescente introdução de máquinas de base microeletrônica e a automação de setores da produção, bem como, e talvez de forma mais intensa, a introdução de inovações associadas ao modelo da acumulação flexível na busca de novos padrões de qualidade e a intensificação do processo de terceirização como estratégia de redução de custos (Leite, 1996). 
As tentativas de modernização e redução de custos em boa parte das empresas deste setor tem levado ao aumento do desemprego e da precarização das condições de trabalho nos maiores centros industriais do Estado de São Paulo, onde este setor está concentrado, com um impacto importante sobre a qualidade de vida dos trabalhadores, homens e mulheres, comprometendo suas condições de saúde através do desencadeamento de processos de adoecimento psico-físicos.

Estudos recentes têm chamado a atenção para o claro bias de gênero presente no processo de reestruturação produtiva. Eles mostram que a inserção nos diferentes postos de trabalho e as condições de trabalho são desiguais para os dois sexos. As mulheres, na sua grande maioria, estão nas empresas subcontratadas e são, em geral, submetidas aos trabalhos mais intensificados e aos postos taylorizados, que exigem delas qualidades vistas como naturalmente femininas, como, por exemplo: cuidado, atenção, higiene e habilidades manuais.

Além desses aspectos, as trabalhadoras estão restritas aos cargos que não necessitam de qualificação e que exigem a capacidade de realizar atividades repetitivas - responsáveis pelos altos índices de LER (Lesões por Esforços Repetitivos) - ou, então, requerem, em alguns casos, a integração de atividades muito simples (Rizek \& Leite, 1998; Cunha, 1999).

Em suma, o que os estudos citados apontam de maneira geral é que o processo de reestruturação tem se dado de forma heterogênea e que os impactos sobre a força de trabalho também são diferentes para homens e mulheres, o que significa que não houve um rompimento com a divisão sexual do trabalho.

Este artigo apresenta algumas reflexões feitas a partir de resultados parciais de uma pesquisa ${ }^{1}$ realizada em quatro empresas dos setores de autopeças e eletroeletrônicos. Os objetivos da pesquisa eram: compreender o impacto dos processos de reestruturação produtiva sobre a divisão sexual do trabalho no interior das empresas, sobre a natureza e as condições de trabalho das mulheres; verificar 
o impacto da reestruturação produtiva e da precarização das condições de trabalho na saúde e na vida reprodutiva das trabalhadoras; conhecer a percepção delas sobre este processo de mudanças e suas conseqüências para suas condições de vida e saúde.

A pesquisa foi realizada em cinco empresas, sendo duas grandes empresas de auto-peças, e uma empresa de porte médio de aparelhos eletroeletrônicos da região do $\mathrm{ABC}$; uma grande empresa de autopeças e uma pequena fabricante de componentes eletroeletrônicos, ambas de Campinas. Foram realizadas visitas às fábricas, conversas com gerentes e observação do processo de trabalho para a compreensão do processo de reestruturação em curso. Foram também aplicados questionários, que continham questões abertas e fechadas, a 48 trabalhadoras.

Não obtivemos autorização da gerência para visitar a empresa de equipamentos eletroeletrônicos do $\mathrm{ABC}$, que chamaremos de Empresa D, e, por esta razão, seu processo de reestrututração foi descrito pela sindicalista que trabalhava na fábrica. Nessa empresa, as trabalhadoras foram entrevistadas mediante contato feito por essa sindicalista. Apesar de termos visitado e realizado observações na Empresa B, não obtivemos autorização do Setor de Recursos Humanos para a aplicação dos questionários com as trabalhadoras, o que inviabilizou a realização das entrevistas. Nas demais empresas, onde obtivermos autorização, os questionários foram aplicados dentro das fábricas, com trabalhadoras que nos foram indicadas pela gerência, o que é uma limitação da pesquisa, pois os resultados poderiam ser diferentes se pudéssemos ter realizado os questionários de acordo com uma amostra construída de forma aleatória.

A Empresa A, localizada em São Bernardo do Campo, é uma grande empresa de autopeças de capital alemão, que produz componentes elétricos para veículos (como a chave de seta, o acionador de vidro elétrico e dos pára-brisas) e tem 1.200 trabalhadores, dos quais 818 (66\%) são mulheres. A Empresa B, localizada em Diadema, produz os componentes eletroeletrônicos dos painéis dos veículos e conta com 800 trabalhadores, dos quais 360 
(45\%) são mulheres. A terceira empresa de autopeças localizada em Campinas, a Empresa C, é uma fabricante de freios de capital alemão e conta com 806 empregados, dos quais apenas 73 (9\%) são mulheres. Essas três empresas fornecem seus produtos para as principais montadoras de carros do país.

Quanto às duas empresas do setor eletroeletrônico, a de médio porte (Empresa D) localiza-se em São Bernardo, e a de pequeno porte (Empresa C), em Campinas. A primeira fabrica máquinas e ferramentas elétricas e conta com 218 empregados, sendo 82 mulheres $(37,6 \%)$. A segunda é uma fabricante de alarmes eletrônicos para automóveis, cuja matriz está na Zona Franca de Manaus, mas a pequena unidade de Campinas presta assistência técnica e realiza o retrabalho dos alarmes defeituosos e, para isso, conta com 151 funcionários, dos quais apenas 28 estão no chão de fábrica e destes, 15 (53\%) são do sexo feminino.

\section{A reestruturação das empresas}

Apesar das diferenças de tamanho, de localização, de tipo de produtos e da porcentagem de mulheres presentes em cada uma destas empresas, foi possível observar um conjunto de elementos comuns aos seus processos de reestruturação e à divisão sexual do trabalho nelas presente.

Nas três grandes empresas de autopeças e na empresa de porte médio fabricante de equipamentos elétricos, observamos um processo de reestruturação em curso, no qual pode ser verificada a adoção de maquinário moderno de controle numérico, bem como de alguns dos novos métodos de gestão, como a qualidade total e as células de produção. Estas novas práticas, no entanto, convivem com máquinas antigas e com linhas de montagem tradicionais, mais próximas do estilo taylorista, com predominância de tarefas parcelizadas e repetitivas. Na pequena empresa $\mathrm{C}$, predomina a linha de montagem tradicional, sem qualquer inovação gerencial, embora estivesse em curso um processo de remodelamento e sinalização do 
processo produtivo, com a finalidade de otimizar o seu uso e prevenir acidentes.

No que diz respeito à divisão sexual do trabalho, em todas as empresas, as mulheres estão concentradas nas linhas de montagem, em funções nas quais predominam os movimentos repetitivos ou o trabalho com peças pequenas que exigem movimentos delicados, agilidade das mãos e acuidade visual. Os homens, em geral, além de trabalharem também nas linhas de montagem, estão mais concentrados nos setores onde o trabalho é considerado pesado e requer grande esforço físico, como nas estamparias, onde operam grandes prensas (nas empresas A e C); na movimentação de material (empresa C) e nos setores insalubres, como o de pintura e de injeção de plástico (empresa A); e no manejo de substâncias tóxicas como na colagem da lona do freio (Empresa C). Eles também são maioria nos setores onde há exigência de conhecimento técnico de nível médio e superior, como nas ferramentarias e nos laboratórios de análise.

Foi, no entanto, possível verificar a presença de poucas mulheres em outras funções, como, por exemplo, na Empresa A, no controle de qualidade e no almoxarifado, realizando o registro de material no computador e na operação de prensas pequenas (onde as mulheres trabalham em duplas) no setor de estamparia. $\mathrm{Na}$ Empresa $\mathrm{C}$, encontramos duas mulheres no laboratório químico, e um único caso de mulher líder de uma célula de usinagem, na qual trabalhavam apenas homens. Esta era a trabalhadora mais antiga da empresa que, além de exercer o papel de líder, tinha sido treinada para trabalhar em um setor em implantação de montagem de válvulas, no qual atuava ao lado de dois trabalhadores

Nas empresas onde o processo de inovações organizacionais estava mais avançado, foram verificados sistemas de células em diferentes estágios de implantação. Na Empresa B, o setor de montagem estava organizado em um sistema de 20 células, nas quais predominavam as mulheres. As células estavam dispostas em forma de $U$ e cada equipe de trabalhadoras realizava a montagem completa de cada peça. Nelas predominava a multifuncionalidade, pois as trabalhadoras não tinham postos fixos e faziam rodízio entre as 
operações. Além disso, era de responsabilidade das trabalhadoras o controle de qualidade de cada peça montada. Na montagem do painel do Corsa, por exemplo, a célula continha quatro trabalhadoras que realizavam todas as 11 operações e, devido ao rodízio entre os postos de trabalho, trabalhavam em pé.

Sistemas de células operando com equipes multifuncionais, sem postos fixos, foram também encontradas nas empresas A, C e D. Na primeira, elas funcionam em apenas alguns turnos. Na segunda, em cada célula, as máquinas estão dispostas em círculos e os trabalhadores e trabalhadoras operam várias máquinas num sistema de rodízio, além de realizarem a tarefa de inspeção de qualidade. A Empresa D tem seu setor de montagem organizado em oito células, nas quais trabalham 28 mulheres. No entanto, apenas três delas se aproximam do modelo toyotista e as demais são organizadas de acordo com o formato tradicional, com base em postos fixos e tarefas taylorizadas.

A multifuncionalidade em geral significa, nessas empresas, não apenas a operação de mais de uma máquina, que inclui o rodízio de tarefas, mas a ampliação de tarefas, com a transferência para as trabalhadoras da responsabilidade pelo controle da qualidade das peças produzidas, além da manutenção, limpeza e organização do local de trabalho.

Em todas essas empresas, contudo, a maior parte da montagem das autopeças é feita ainda em linhas de montagem tradicionais ou em bancadas de trabalho, geralmente em ambientes sem muita ventilação e com alto nível de ruído. Mesmo nessas plantas, é possível ocorrer rodízios de tarefas e um certo grau de cuidado com a qualidade das peças.

\section{O controle e a segurança}

Os novos métodos de organização da produção trazem novas formas de controle do trabalho ou até mantém algumas das formas tradicionais. 
Na Empresa A, por exemplo, na área de produção há um balcão em um nível acima do chão de fábrica, que permite uma visualização de toda a área. Neste balcão trabalham engenheiros e técnicos responsáveis pelo planejamento da produção diária. A localização do balcão atende, segundo a funcionária que nos acompanhou, "à necessidade de controle da produção e dos(as) trabalhadores(as)." Esta forma de controle pode ser pensada a partir da idéia do Panóptico de Foucault (1993, p. 126, 130, 135, 173), no qual o controle pode ser exercido sem que os(as) controlados(as) percebam: "o olhar está alerta em toda parte".

Mas além destas formas tradicionais de controle, presentes também na figura dos líderes das células ou dos encarregados de setor, há o controle do ritmo e da intensidade do trabalho feito pelas próprias máquinas e pela programação da velocidade das linhas de montagem. Além disto, há novos dispositivos de controle, como o que encontramos na Empresa B. Nesta, na entrada de cada célula há um painel com a identidade de cada trabalhadora, suas habilidades e a função que cada uma realiza. Nele estão estabelecidas as orientações gerais para o bom andamento do processo de produção, assim como o número de peças fabricado por hora e o número de peças com defeito. Através desse painel é feito também o controle das saídas, por um dispositivo acionado eletronicamente, acendendo uma luz assim que a trabalhadora deixa o seu posto, que se apaga no seu retorno. Este dispositivo transforma a estratégia do controle das idas ao banheiro, que antes era feito por meio das chefias diretas.

O painel permite, portanto, um controle completo do processo de produção de cada célula, de sua produtividade, dos erros e paradas, bem como um controle direto sobre as próprias trabalhadoras.

A esta forma externa de controle, soma-se, em geral em todas as empresas, o controle interno a cada célula ou equipe de trabalho, pois a pressão para o cumprimento de metas de produção e para o aumento da qualidade faz com que as(os) próprias(os) trabalhadoras(es) controlem umas(uns) as(aos) outras(os). Estas são formas daquilo que Dejours (1993, p. 150-174) chamou de controle subjetivo. 
Um outro aspecto importante e geralmente associado com o processo de reestruturação produtiva é a preocupação das empresas com a questão da segurança dos(as) trabalhadores(as) como meio de evitar ou reduzir acidentes e a ocorrência de doenças ocupacionais. Essa preocupação, presente em todas as cinco plantas pesquisadas, é decorrente tanto da pressão sindical e das CIPAs de um lado, quanto da necessidade de as próprias empresas reduzirem custos com assistência a trabalhadores(as) acidentados(as) ou associados à estabilidade de trabalhadores(as) que adquiriram doenças ocupacionais, como é o caso das LER.

Pesquisas anteriores mostraram que o setor metalúrgico está entre os que apresentam mais casos de LER/DORT (doenças osteomusculares relacionadas ao trabalho) e as mulheres constituem o grupo mais atingido por este tipo de doença, devido, principalmente, à sua concentração nas linhas de montagem e postos marcados pelo ritmo intenso e por tarefas repetitivas (Barreto, 1997; Araújo, Ferreira \& Amorim, 1999). Nas cinco empresas visitadas nesta pesquisa, as linhas de montagem foram, em geral, identificadas como locais de alta incidência das LER/DORT. Em todas elas, verificamos no discurso da gerência uma preocupação com a aquisição de máquinas dotadas de dispositivos de segurança contra acidentes, com a ergonomia dos instrumentos e bancadas de trabalho, bem como com a rotação de tarefas e até o uso da ginástica laboral como mecanismos destinados a evitar a aquisição das LER.

Chamou-nos a atenção a aquisição de máquinas com acionamento automático - cujo acionamento ocupa as duas mãos dos operadores de modo a evitar acidentes -, principalmente prensas e injetoras de plástico, em quatro das empresas visitadas. Observamos também a introdução na Empresa $\mathrm{C}$ - no setor da montagem do Booster (ou servo-freio) -, de dispositivos à prova de erro, conhecidos como o Poka-Yoke japonês. Estes dispositivos são inseridos na máquina de modo a evitar que peças sejam encaixadas em posição errada, comprometendo o produto, quebrando o equipamento ou causando acidentes. O Poka-Yoke é um instrumento de controle do processo de trabalho, que utiliza o saber dos operários, os quais são, 
geralmente, os inventores destes dispositivos, para aumentar o nível de padronização das operações, visando à melhoria da segurança e da qualidade.

\section{A percepção das trabalhadoras}

O processo de reestruturação produtiva altera o perfil dos trabalhadores e trabalhadoras que permanecem empregados. Nas empresas estudadas, a mudança nas características da mão-de-obra feminina tem um papel importante na política de diminuição do custo do trabalho. As trabalhadoras destas empresas são, em geral, jovens, na idade reprodutiva, variando na faixa de 20 a 45 anos e tem um grau relativamente elevado de escolaridade. É significativo que $40 \%$ delas tenham o segundo grau completo e cerca de $47 \%$ tenham entre o primeiro grau completo e o segundo grau incompleto. A despeito disso, $71 \%$ das trabalhadoras não estavam estudando no momento da pesquisa e apenas $2 \%$ delas concluíram o curso universitário, dados que demonstram a exclusão no acesso a níveis mais elevados de escolaridade.

Outro aspecto revelador que confirma a mudança que vem ocorrendo no perfil das famílias brasileiras, é o fato de $38 \%$ das trabalhadoras entrevistadas serem chefes de família. Esta situação traz como problemática para estas mulheres a necessidade de conciliar o trabalho extradoméstico e o trabalho doméstico - a chamada dupla jornada - e pode ser vista como uma das possíveis causas de estresse e adoecimento em decorrência do trabalho.

De acordo com as respostas das entrevistadas, as exigências atuais das empresas no processo de recrutamento são: o nível de escolaridade, em geral, o primeiro ou segundo grau completos $(20 \%$ das respostas); atestados de saúde (19\%); experiência anterior de trabalho (13\%); e facilidade de comunicação (9\%). No entanto, apareceram também nas respostas outras exigências, como: bom relacionamento familiar, não ter filhos(as), ser solteira, ter boa aparência, ter facilidade de adaptação às mudanças, e, não ter tido 
envolvimento com greves. Estas exigências demonstram as novas habilidades e atitudes requeridas pelas empresas para assegurar uma mão-de-obra feminina capaz de se adaptar às suas necessidades de melhoria da qualidade, de polivalência e de comprometimento com seus objetivos e metas de produtividade.

Quanto aos lugares que ocupam no processo produtivo, as mulheres estão em sua grande maioria desempenhando funções de operadoras de máquinas funcionais $(56,7 \%)$ ou multifuncionais $(21 \%)$, ou são auxiliares de produção (9\%), o que significa, quase sempre, postos em que prevalece o trabalho repetitivo e intenso. Quando são postos considerados multifuncionais, isto significa que há rodízio ou agregação de tarefas simples nas linhas de montagem ou nas células. O esforço das empresas de adequação da força de trabalho às habilidades e atitudes exigidas pelos novos métodos gerenciais se evidencia nas respostas das trabalhadoras que afirmaram ter passado, nos últimos anos, por alguma forma de treinamento $(60,9 \%)$. No entanto, uma parcela significativa delas $(39,1 \%)$ não fez qualquer curso ou treinamento para realizar novas tarefas. Isto pode ser um indício de que as empresas não dão a todas o mesmo acesso à capacitação para o exercício de novas funções.

As respostas aos questionários mostraram que as trabalhadoras tinham uma nítida percepção do processo de reestruturação por que passaram as empresas nas quais trabalhavam. Parte significativa delas assimilou vários dos conceitos relativos aos novos métodos de gestão, hoje predominantes no discurso e na prática gerenciais.

A percepção de que as empresas pesquisadas passaram ou estavam passando por um processo de reestruturação e o significado deste processo aparece nas respostas de cerca de $66 \%$ das entrevistadas. A introdução de modificações na organização do trabalho foi mencionada por $92 \%$ das entrevistadas. Como exemplos das mudanças que vinham ocorrendo citaram a reorganização do setor (30\%), mudanças no processo de trabalho (21\%), modificações no maquinário (18\%) ou introdução de novas máquinas $(2 \%)$, melhorias nas condições de trabalho $(7 \%)$, redução do número de 
trabalhadores(as) (5\%), aumento de novas tarefas (5\%) e da produção (5\%), as trabalhadoras são mais ouvidas (2\%) ou tem mais liberdade de opinião $(2 \%)$.

$\mathrm{O}$ fato de apenas $2 \%$ das mulheres terem se referido à introdução de novas máquinas, parece confirmar um dado presente em outras pesquisas de que as trabalhadoras, em geral, tem sido excluídas dos setores onde ocorre a introdução de equipamentos mais modernos e sofisticados. Fala-se inclusive de masculinização dos setores automatizados ou nos quais predominam máquinas computadorizadas (Rizek \& Leite, 1998; Araújo \& Amorim, 2002).

Por outro lado, as trabalhadoras percebem a introdução de mudanças incrementais nas máquinas que operam. Este processo de mudança tecnológica para aumentar a produção exigiu das trabalhadoras diferentes formas de adaptação ao ritmo das máquinas (o que foi afirmado por $82 \%$ delas), com conseqüências muitas vezes perversas para a sua qualidade de vida.

Quanto às inovações gerenciais, a qualidade total aparece como um programa conhecido por $95,7 \%$ das entrevistadas. De acordo com $92,5 \%$ delas, este método havia sido adotado nas empresas em que trabalhavam e $90,4 \%$ avaliaram positivamente a sua implementação na empresa.

A percepção da melhoria das condições de trabalho, apesar de ter sido a reposta de apenas 7\% das entrevistadas, pode estar relacionada com modificações ergonômicas e no ambiente de trabalho, no sentido de limpeza, iluminação e ventilação, e que aparecem como uma preocupação das empresas associada à busca de qualidade e redução de custos. Quando perguntadas sobre o que mudou em seu setor de trabalho, 46,3\% afirmaram que a empresa passou a se preocupar mais em prevenir acidentes e doenças ocupacionais; $27,5 \%$ disseram que seu trabalho ficou menos perigoso e $15 \%$ que seu trabalho ficou menos insalubre. Entretanto, uma pequena parte das trabalhadoras, apresenta uma visão oposta (Tabela 1), afirmando que seu trabalho ficou mais insalubre $(8,8 \%)$ ou mais perigoso $(1,3 \%)$. 


\section{Tabela 1 - Percepção das trabalhadoras sobre as mudanças no setor onde trabalham}

\begin{tabular}{|l|c|c|}
\hline $\begin{array}{l}\text { Com as modificações no seu setor de trabalho, você } \\
\text { tem percebido que }\end{array}$ & Números & Porcentagem \\
\hline Seu trabalho ficou mais perigoso & 1 & $2 \%$ \\
\hline Seu trabalho ficou menos perigoso & 22 & $45,8 \%$ \\
\hline Seu trabalho ficou mais insalubre & 7 & $14,5 \%$ \\
\hline Seu trabalho ficou menos insalubre & 12 & $25 \%$ \\
\hline $\begin{array}{l}\text { A empresa passou a se preocupar mais em prevenir } \\
\text { doenças e acidentes de trabalho }\end{array}$ & 37 & $77 \%$ \\
\hline $\begin{array}{l}\text { A empresa não está preocupada em prevenir doenças e } \\
\text { acidentes de trabalho }\end{array}$ & 1 & $2 \%$ \\
\hline
\end{tabular}

Além disto, sobre a prevenção contra os riscos físicos e químicos nas empresas pesquisadas, $41 \%$ das trabalhadoras mencionaram apenas palestras e vacinas como ações preventivas, 0 que revela uma des-responsabilização das empresas no que toca às questões de segurança e de saúde no trabalho.

Em relação às mudanças associadas à reestruturação produtiva, para 19,7\% das trabalhadoras elas levaram a "uma produção maior e com menos erros", para 17,8\% "provocaram menores interrupções na rotina do trabalho", para 16,45\% "levaram a uma maior preocupação com o trabalho dos colegas", para 13,2\% provocaram "maior esforço físico e mental na execução do trabalho" e para 7,2\% "aumentou o número de máquinas que operam” (Gráfico 1).

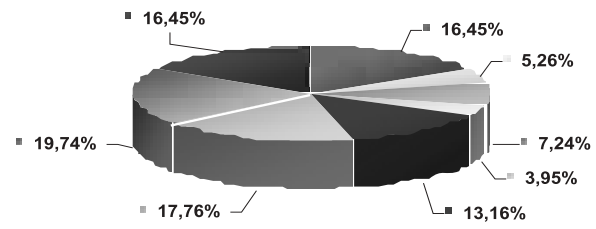

n tarefas aumentadas pela incorporação de outras que eram executados por outros tarefas aumentadas pela incorporação de tarefas que não existiam antes no setor - aumentou o $\mathrm{n}^{\circ}$ de máquinas operadas

reduziu o $n^{\circ}$ de máquinas operadas

- exigiram maior esforço físico e mental na execução do trabalho uprovocaram menores interrupções na rotina de trabalho

- levaram a uma produção maior e com menores erros

- levaram a uma maior preocupação com o trabalho dos seus colegas

Gráfico 1 - Implicações do processo de reestrutuação produtiva para as mulheres 
Estas respostas demonstram uma visão clara das trabalhadoras sobre as implicações do processo de reestruturação para o seu trabalho e apontam para os objetivos centrais deste processo: a melhoria da qualidade da produção com menor custo e o aumento da produtividade do trabalho através da redução dos erros e defeitos e da eliminação dos tempos mortos. Isto implica o aumento das tarefas e das máquinas operadas por trabalhador(a), a intensificação do ritmo de trabalho e, portanto, o aumento da carga de trabalho e maior esforço físico e mental dos(as) trabalhadores(as). Há um nítido contraste entre as novas exigências das empresas e o que as trabalhadoras recebem em troca do seu maior esforço e comprometimento: $88,4 \%$ das entrevistadas afirmaram que, apesar das mudanças no seu trabalho, o seu salário-base diminuiu, enquanto apenas $11,6 \%$ mencionaram uma elevação salarial.

Um dos aspectos centrais das mudanças na natureza do trabalho que acompanham os novos métodos de gestão diz respeito à chamada polivalência. A importância da mudança nos postos de trabalho nas empresa pesquisadas pode ser atestada pelas respostas de $96,9 \%$ das trabalhadoras que se consideravam polivalentes. Isto pode significar uma assimilação acrítica do discurso gerencial, já que, como vimos, parte das mulheres permanecia em postos fixos enquanto outras realizavam apenas a rotação de algumas poucas tarefas simples.

No entanto, a maioria das entrevistadas mostrou ter uma noção clara do significado deste termo. Quando perguntadas porque se consideravam polivalentes, 72,4\% delas afirmaram estarem capacitadas para a realização de várias tarefas, enquanto 17,2 \% falaram da facilidade de adaptação às novas formas da organização do trabalho.

A maioria das trabalhadoras $(54,8 \%)$ percebeu a ocorrência de um processo de terceirização associado às modificações introduzidas nas empresas em que trabalhavam e afirmaram a existência de diferenças salariais entre elas e as trabalhadoras das empresas subcontratadas. No entanto, a sua percepção sobre as 
condições de trabalho destas últimas foi diferenciada: $43,7 \%$ das entrevistadas disseram que as trabalhadoras subcontratadas tinham a mesma jornada de trabalho, 20,8\% afirmaram que, em geral, elas tinham qualificações equivalentes, $25 \%$ que exerciam a mesma função, $12,5 \%$ que ganhavam o mesmo salário e 14,5 que elas recebiam os mesmos benefícios e vantagens. Inversamente, para $6,2 \%$ das entrevistadas, as trabalhadoras vinculadas às empresas subcontratadas eram menos qualificadas, para $4 \%$ elas trabalhavam um maior número de horas, enquanto para $48 \%$ elas recebiam um salário menor.

Estas visões quase opostas podem indicar a presença de realidades diferentes no que diz respeito às condições de trabalho em empresas subcontratadas pelas companhias pesquisadas. Entretanto, como as respostas não eram excludentes, o que chama a atenção é o fato de uma parcela considerável das entrevistadas perceber que as trabalhadoras das empresas terceiras apesar de, em geral, terem qualificações equivalentes, a mesma jornada de trabalho, participarem da organização das atividades do dia-a-dia (35\% das respostas) e exercerem as mesmas funções das que trabalham nas empresas contratantes, recebiam salários inferiores aos destas últimas. Essa percepção confirma o que vários estudos mostraram sobre a precarização do trabalho nas empresas terceiras do setor metal-mecânico e eletroeletrônico (Araújo \& Gitahy, 2003; Delgado, 1994, Gitahy,1994, Druck, 1994).

\section{A percepção das conseqüências da reestruturação para a saúde}

O conceito de saúde ocupacional surgiu depois da Segunda Guerra Mundial, com a incapacidade de a medicina do trabalho responder às problemáticas de saúde emergentes do processo de produção (Dias \& Mendes, 1991). Naquele momento, como ainda hoje, diferentemente do que sucedia e sucede com os dramáticos acidentes de trabalho, principalmente os da indústria pesada, os problemas de saúde das mulheres não eram vistos como relacionados 
com o trabalho, sendo enfocados apenas do ponto de vista da prevenção dos riscos à gravidez, reforçando a visão biologicista e funcionalista sobre a mulher (Oliveira, 1999).

Berlinguer, um dos raríssimos médicos sanitaristas que pesquisou e refletiu sobre as diferentes questões das mulheres no mundo do trabalho desde a Idade Média até a atualidade, evidenciou a dupla jornada de trabalho das mulheres e sua interferência no ritmo das tarefas como questões ligadas à qualificação profissional:

A desqualificação, correspondente ao nível profissional efetivamente inferior da mulher, representa o resultado do condicionamento a uma situação social e psicológica à qual a mulher está sujeita e, sobre o plano social, a qualificação e o conhecimento profissional constituem fatores de segurança, não só para a manutenção do posto de trabalho, mas para a superação das situações de conflito que surgem para aqueles que desejam vencer no trabalho. [...] a mulher instruída e qualificada pode ter uma personalidade mais segura em suas funções de mulher e mãe, não só pela maior contribuição à família, mas porque pode, dessa maneira, reinserir-se mais facilmente na atividade produtiva depois da licença de gravidez e aleitamento. (Berlinger, 1978).

Isso confirma nossa tese de que as trabalhadoras para se manterem no emprego são, freqüentemente, colocadas em situações dilacerantes diante da escolha da maternidade. Feita esta escolha, nova situação se coloca entre o aleitamento e o desmame precoce, que pode provocar seqüelas profundas na esfera psíquica.

Sob o taylorismo, predominaram a tecnologia da submissão e a disciplinarização do corpo, gerando exigências fisiológicas até então desconhecidas, tais como a neutralização da atividade mental decorrente da separação entre as atividades manual e intelectual. Em consequiência, os(as) trabalhadores(as) não tinham conhecimento do processo integral do trabalho, sequer sabiam o porquê de suas tarefas. O corpo dócil e vigiado restava sem defesa, fragilizado e privado da capacidade de pensar.

Aqui podemos traçar com nitidez os diferentes impactos das práticas tayloristas na qualidade de vida dos homens e das mulheres, 
pois a construção dos adestramentos corporais - onde se alojam os diferentes dispositivos que produzem a docilidade e anulam as resistências individuais e coletivas - é marcada pelas relações de gênero, com significados reais e simbólicos discriminatórios (Foucault, 1977).

A exigência de uma restruturação das tarefas foi a primeira decorrência do esgotamento taylorista e do fordismo.

O movimento operário, como um dos sujeitos do movimento de 1968, expressava, na recusa à sociedade de consumo e à alienação do trabalho, os novos sentidos da palavra que passava a se libertar dos significados normativos e adestrados, re-significando as esferas do prazer e da libido. O movimento feminista teve uma importância muito grande nesse reordenamento das palavras e das idéias, ao introduzir a dimensão da divisão sexual nos mundos do trabalho e da casa como elemento estruturante da vida cotidiana.

Scott (1992) já afirmava, na década de 1970, a variabilidade histórica do termo mulheres e de que modo ele se alterou. No decorrer da industrialização, por exemplo, a designação mulheres trabalhadoras como categoria separada dos trabalhadores criou novas percepções sociais do que significava ser uma mulher. Ainda nessa época, assistimos no Brasil ao ingresso das mulheres no mercado de trabalho de forma intensa e diversificada, sem retrocesso, apesar das crises econômicas que abalaram o país. As mulheres estavam em diferentes profissões, particularmente naquelas que exigiam destreza manual e eram consideradas guetos femininos de trabalho; recebiam um salário que correspondia, por exemplo, na cidade de São Paulo, a 53\% do salário dos homens, embora 27\% delas fossem chefes de família, quebrando o mito de que trabalhavam fora só para ter dinheiro no bolso.

Segundo Messing (1993), o tipo de trabalho que as mulheres realizam origina problemas de saúde que, a curto prazo, não são nem agudos nem dramáticos, mas tornam penosa a vida de todos os dias.

As consequiências do avanço tecnológico das últimas décadas juntamente com a exigência de qualidade, de envolvimento com as 
metas de produtividade, a intensificação do ritmo de trabalho, caracterizando, portanto, uma hipersolicitação, determinara a mudança no perfil epidemiológico dos riscos à saúde, agregando, às tradicionais doenças do mundo do trabalho, o sofrimento mental e o assédio moral, até hoje pouco reconhecidos como tais. Esse quadro interfere na vida sexual e reprodutiva das trabalhadoras que são as mais penalizadas pela clivagem de gênero que as diferencia sexualmente ao nascer, viver, trabalhar, adoecer e morrer.

Nesta pesquisa, as respostas das trabalhadoras sobre o impacto da reestruturação produtiva em suas condições de vida e saúde, reafirmaram resultados de outros estudos que articulam saúde, trabalho e gênero (Barreto, 2003; Scavone 2002; Brito 2000; Oliveira 2003). Ou seja, as trabalhadoras, em sua maioria, tiveram dificuldade de fazer o nexo do trabalho com suas condições de vida e saúde, provavelmente pelo medo de entrarem na malha do desemprego.

Dentre as trabalhadoras entrevistadas, $81,3 \%$ consideraram boas as suas condições de saúde, enquanto $12,5 \%$ as perceberam como ruins. Quando as questões se tornaram mais específicas, as respostas se alteraram. Questionadas se já adoeceram em decorrência de condições nocivas do trabalho, apenas $24,2 \%$ das trabalhadoras responderam afirmativamente. Entretanto, 31,3\% das entrevistadas reconheceram alterações em sua saúde depois que começaram a trabalhar, enquanto 58,3\% delas afirmaram o contrário, o que pode demonstrar uma certa dificuldade destas operárias em perceber a relação direta ou indireta entre saúde e trabalho. Destacamse aqui duas questões: 1) o fato de que nenhum(a) trabalhador(a) deveria adoecer devido às suas condições de trabalho; 2) a relação com o tempo de trabalho na empresa, que torna mais difícil estabelecer o nexo saúde-doença-trabalho, pois apenas $23 \%$ das trabalhadoras afirmaram ter trabalhado sempre na mesma empresa, enquanto $77 \%$ trabalharam em várias outras.

Uma análise mais detalhada das respostas, à luz das informações relativas aos objetivos e mecanismos da reestruturação produtiva, permite elucidar os impactos significativos desse processo de mudanças na saúde das trabalhadoras. 


\section{Os efeitos da hipersolicitação}

Vários estudos já demostraram que um dos maiores impactos da reestruturação produtiva sobre a saúde das trabalhadoras e trabalhadores tem sido a epidemia das LER/DORTs (Araújo, Ferreira \& Amorim, 1999; Oliveira \& Barreto, 1997; Ribeiro, 1995; Almeida, 1995; Brandimiller, 1996). Apesar dessa doença ter sido inicialmente detectada como epidemia no setor bancário, observou-se na indústria, e principalmente no setor metal-mecânico, um forte crescimento do número de casos a partir de meados da década de 90 . Neste último setor, foi a intensificação das mudanças na organização do trabalho, marcadas pelo enxugamento de postos de trabalho, pela terceirização, pela manutenção de postos de trabalho taylorizados e a crescente pressão por produtividade, que levaram a esse quadro epidêmico.

As respostas das trabalhadoras entrevistadas neste estudo confirmaram a presença importante das LER/DORTs nas empresas dos segmentos de autopeças e eletroeletrônico: 89,6\% delas afirmaram a existência de trabalhadoras com LER nas empresas nas quais trabalhavam. No entanto, quando perguntadas sobre os problemas de saúde que elas identificavam como sendo causados pelas modificações no seu setor de trabalho, apenas $24 \%$ se referiram à LER. Uma outra parte, contudo, mencionou outros sintomas: $21 \%$ delas mencionaram problemas de coluna, $8 \%$ a fadiga muscular pelo cansaço físico e 7\% problemas nervosos que já foram indicados pela literatura (Silva \& Jardim, 1997) como sendo sintomas ligados às LER.

Foram também identificados outros problemas de saúde: $12 \%$ referiram-se a problemas de estômago, $2 \%$ a problemas de intestino (relacionados à tensão e a algum tipo de pressão) e $26 \%$ a outros tipos de doenças. O importante a ressaltar em todas essas manifestações é o fato de que elas estão relacionadas com o trabalho repetitivo e com a pressão excessiva sofrida no trabalho, seja subjetiva ou objetiva (Gráfico 2). 


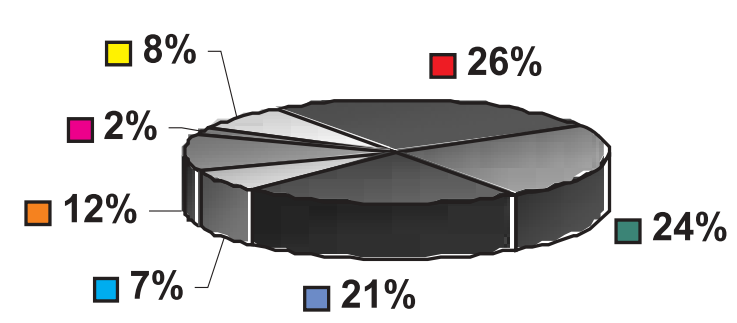

$\square$ LER

$\square$ problemas nervosos

$\square$ problemas de intestino

outros $\square$ problema de coluna

$\square$ problemas de estômago

$\square$ fadiga muscular

\section{Gráfico 2 - Principais problemas de saúde das mulheres entrevistadas causados pelas mudanças no setor de trabalho}

Nesse sentido, estas respostas nos permitem dizer que é alto o número de trabalhadoras que adoeceram por causa da presença de condições nocivas nas empresas. Os fatores do adoecimento, segundo a percepção das trabalhadoras, foram em ordem decrescente: trabalho repetitivo, postura incorreta, muita cobrança, trabalho intenso e cadeiras inadequadas. Estes são fatores que transversam os aspectos físicos, ergonômicos, psíquicos e sociais da organização do trabalho e exigem uma abordagem interdisciplinar.

Apesar de não terem identificado, nas repostas acima referidas, o adoecimento como causado pelas mudanças nas condições de trabalho, é importante ressaltar que $54,1 \%$ das trabalhadoras afirmaram sofrer de muitas dores físicas, que limitavam sua vida cotidiana. As regiões do corpo nas quais estas dores se localizavam eram: braços, coluna, ombros, pernas, mãos e pescoço (Gráfico 2) dores que constituem os sintomas das LER - e, nem sempre, são percebidas enquanto tais pelas trabalhadoras ou reconhecidas pelas empresas. 
As dores nas pernas, pés e joelhos dizem respeito, em geral, à postura provocada pelas condições ergonômicas inadequadas para as mulheres. Cabe salientar que as dores de cabeça e de estômago, também mencionadas pelas trabalhadoras, constituem prováveis sintomas de estresse e de sofrimento mental provocado pelo excesso de pressão das chefias para o atendimento de metas de produção.

O impacto da reestruturação produtiva na vida sexual e reprodutiva das trabalhadoras torna visível essa dimensão específica de gênero, em geral desconsiderada quando se trata da intersecção entre a saúde das mulheres e suas condições de trabalho. A maioria das operárias entrevistadas não parece perceber a existência de qualquer relação entre seu trabalho e sua sexualidade: $68,7 \%$ afirmaram que o trabalho não influencia na sua vida sexual, enquanto apenas $12,5 \%$ reconheceram esta influência. Essa questão tem sido objeto de reflexão em estudos anteriores (Oliveira, 1996, 1999, 2000), nos quais a ambigüidade das respostas das trabalhadoras desenha uma complexa linha de fronteira entre as esferas da subjetividade e da objetividade.

A influência do trabalho na vida sexual e reprodutiva pode ser identificada através dos depoimentos de operárias que vivenciam a menstruação com desconforto, irritabilidade, depressão, medo e vergonha. As alterações na menstruação como resultado das condições de trabalho, conforme a percepção dessas trabalhadoras, são os desequilíbrios no ciclo menstrual, o aumento do fluxo, as cólicas e a maior fadiga muscular, basicamente devido ao excesso de sobrecarga, ausência de pausas e pressão para a produtividade.

Algumas trabalhadoras mencionaram como efeitos nocivos do trabalho para a gravidez: o trabalho pesado, a ansiedade para cumprir a meta de produtividade, o trabalho em pé e os odores de tinta que, agregados às tarefas do trabalho doméstico, foram vistos como uma sobrecarga desumana para as mulheres.

Perguntadas sobre o uso de contraceptivo, 47,9\% das entrevistadas disseram não utilizar e apenas $20,8 \%$ afirmaram estar usando algum tipo, sendo os mais freqüentes, em ordem decrescente, 
a pílula, a laqueadura, a camisinha e o contraceptivo injetável. Os motivos que levaram as trabalhadoras a se laquearem foram: o desejo de não ter mais filhos(as), os riscos para a saúde e as dificuldades financeiras e sociais.

A maternidade foi apontada como uma condição que interfere no trabalho por $50 \%$ das entrevistadas, por aumentar a responsabilidade da mulher e tornar a jornada de trabalho mais cansativa. Esta questão é emblemática da perversidade que constitui para as mulheres o fato de, freqüentemente, serem colocadas diante da escolha entre o emprego ou a maternidade. Aqui é importante ressaltar a extensa jornada de trabalho das mulheres, numa peregrinação permanente entre o tempo do trabalho doméstico e o tempo do trabalho extradoméstico.

A hipersolicitação às trabalhadoras e seus impactos sobre a saúde - dada a sua invisibilidade -, tem sido pouco estudada. Um dos poucos estudos que aborda o problema (Oliveira, 1996), mostrou que estes impactos são percebidos nos efeitos não específicos na saúde física e no sofrimento mental que, no caso das mulheres, aparecem de diferentes maneiras associados seja à depressão, seja à vida reprodutiva e sexual, e estão relacionados à dupla jornada de trabalho e à sua intensificação no contexto da reestruturação produtiva.

\section{As agressões à dignidade e à auto-estima}

São diversas as agressões às condições de vida e saúde das trabalhadoras no cenário da reestruturação reprodutiva, no entanto, nas empresas estudadas apenas algumas dessas agressões foram mencionadas pelas trabalhadoras.

A primeira é a insegurança econômica que cresce com a política de enxugamento das empresas e o medo constante do desemprego. A segunda diz respeito ao trabalho real no sentido da força de trabalho despendida e o valor por ele recebido. Os baixos salários recebidos representam o não reconhecimento pelo saber e 
pelo fazer das trabalhadoras. Outra forma de agressão à dignidade são os controles informatizados pelos painéis eletrônicos, que constituem uma estratégia de controle sutil e eficaz das paradas e das idas ao banheiro, ao substituir a antiga chapinha ou chave.

Os efeitos dessas agressões não têm visibilidade quantitativa porque são expressões de sofrimento psicológico e mental. O medo é uma das manifestações mais recorrentes entre os(as) trabalhadores(as), como o medo de perder o emprego, de não conseguir agüentar as pressões por mais produtividade, de não resistir às diferentes formas de controle subjetivo expressas pelas cantadas das chefias e pelas violências sexuais; o medo de não agüentar firme o tempo todo, sem relaxar, sem se importar em se machucar, sem se ferir e sem adoecer.

As trabalhadoras entrevistadas neste estudo relataram situações de ameaças, cobranças, constrangimentos na relação tanto com os chefes imediatos quanto com os líderes de grupos ou células, que transformam o ambiente de trabalho em um espaço de desconforto e sofrimento. Este quadro é conhecido, mas ainda pouco estudado, como o assédio moral ou mobbing (Barreto, 2003; Hirigoyen, 2001). $\mathrm{O}$ assédio moral constitui hoje uma das mais perversas estratégias de controle do trabalho e se expressa na hipersolicitação das trabalhadoras colocando-as em uma condição de humilhadas. Como mostra Barreto (2003, p. 203), as mulheres são mais freqüentemente colocadas em situações de humilhação "quando comparadas aos homens (...), evidenciando um controle maior da força de trabalho feminina". O assédio moral provoca nas trabalhadoras o "excesso" de preocupação com a qualidade da produção e com o cumprimento das metas de produtividade, e a sensação constante de estar sempre devendo alguma coisa. Frente às situações de humilhação, as trabalhadoras têm de buscar estratégias individuais para sobreviverem já que estas situações não são assumidas, reconhecidas e tampouco resolvidas pela organização social do trabalho. 


\section{Finalizando}

Com esta pesquisa pode-se realizar um diálogo entre dois campos de conhecimento - as ciências humanas e as ciências da saúde - importantes para pensar o(s) mundo(s) do trabalho, sob a égide da reestruturação produtiva: parafraseando W. Benjamin (1987): “... a perspectiva da rua de mão dupla..." e, neste trabalho, os olhares se entrecruzaram permanentemente. Foi assim, que se possibilitou apreender os aspectos invisíveis dos impactos da reestruturação produtiva nas condições de vida e saúde das trabalhadoras.

Entrar no chão da fábrica, observar o processo de produção e os lugares onde estão as mulheres, nos levou a problematizar os custos sociais, físicos e psíquicos para elas das novas formas de organização do trabalho.

A pesquisa mostrou que o processo de reestruturação nas empresas estudadas seguiu um padrão heterogêneo, já conhecido no setor metal-mecânico, que mescla a introdução de equipamentos modernos e novos métodos gerenciais, voltados principalmente para a melhoria da qualidade, para a flexibilidade e redução de custos, com as antigas práticas tayloristas de postos fixos, tarefas parcelizadas e repetitivas. Como já observado em outros estudos sobre o setor, as mudanças estão mais presentes nas grandes empresas, mas também nas pequenas permaneceram condições nocivas de trabalho, aliadas à intensificação do ritmo e da pressão sobre os trabalhadores e trabalhadoras.

As mudanças nas formas de uso da força de trabalho decorrentes da reestrutração das empresas não alteraram, no entanto, de forma significativa, a divisão sexual do trabalho, na medida em que as trabalhadoras permaneceram, na sua grande maioria, excluídas dos setores modernizados tecnologicamente e concentradas nos postos taylorizados, marcados por tarefas repetitivas que exigiam, em geral, movimentos delicados, atenção aos detalhes e acuidade visual.

Apesar desses fortes elementos de continuidade, importantes alterações ocorreram no conteúdo das tarefas, com a adoção da 
multifuncionalidade e a conseqüente transferência de responsabilidade para os(as) trabalhadores(as) da produção. Além disso, foram observadas novas exigências de comprometimento com os objetivos e metas de produtividade das empresas que surgem associadas a diversas formas de pressão invisíveis que atingem a esfera da subjetividade daqueles(as) que trabalham.

Outra mudança importante foi percebida no controle do trabalho, que passou a contar com formas mais eficazes e diretas, como os painéis eletrônicos e a pressão constante das chefias, e com formas mais indiretas e sutis, como aquelas que se realizam através de treinamentos e no interior das células pelos próprios colegas de trabalho.

As trabalhadoras entrevistadas demonstraram ter uma nítida percepção das mudanças introduzidas nas empresas pelo processo de reestruturação. Chamou a atenção o fato de a maior parte delas mencionarem como resultados dessas mudanças, de um lado, melhorias nas condições de trabalho, que, de fato, ocorreram em alguns setores e, de outro, a intensificação do ritmo de trabalho com o aumento da produção e a redução de tempos mortos -, e a necessidade de maior envolvimento, expressa na preocupação com a qualidade e com o trabalho dos outros, gerando maior esforço físico e mental.

No que diz respeito aos impactos nas condições de vida e saúde das trabalhadoras, a pesquisa mostrou que eles atingem os vários aspectos da saúde bio-psíquica e social. Embora as trabalhadoras tenham manifestado dificuldade em articular o nexo entre o processo de adoecimento e as condições de trabalho, suas falas trouxeram elementos que permitiram identificar a presença de sintomas de deterioração de aspectos de sua vida sexual e reprodutiva, mas, principalmente do acometimento das LER e manifestações do sofrimento mental.

As LER e o assédio moral são hoje a ponta do iceberg dos impactos perversos da reestruturação produtiva para as mulheres trabalhadoras. Nas manifestações dos sintomas das LER fica evidente 
o recorte de gênero, dado que é entre as mulheres que elas aparecem com maior importância pela sua concentração em tarefas que exigem movimentos repetitivos, monótonos e, em alguns setores, bastante solitários. De modo similar, são as mulheres os principais alvos de constrangimentos e humilhações presentes principalmente na relação com os chefes do sexo masculino, mas também nas dificuldades encontradas para ter acesso a treinamentos, a postos mais qualificados e a melhores salários, bem como a sua culpabilização pelas dificuldades de compatibilizar a jornada do trabalho extradoméstico com as tarefas e necessidades do trabalho reprodutivo que, na maioria dos casos, elas ainda assumem integralmente.

A baixa auto-estima expressa nos sentimentos de não ser capaz de fazer mais, de não conseguir progredir dentro da empresa, de se culpar por não ter se qualificado o suficiente, de não ter se preparado para enfrentar a rapidez das mudanças, mostram a força e a agressividade do discurso gerencial que transfere, o tempo todo, responsabilidades para os(as) trabalhadores(as). Como afirmou uma trabalhadora entrevistada depois de ter recebido flores na empresa por ocasião do Dia das Mães: "de que adianta ganhar flores se eu nunca vou sair deste lugar?’.

\section{Notas}

1 Esta pesquisa contou com a participação dos estagiários Alessandra de Oliveira Carvalho, César Augusto Inoue, Érica Marcondes Gonçalves Leite e Renata Ribeiro Trigo, da UNIFESP; Beatriz Cardoso Cordeiro, da UNICAMP, e Rosimar Dias Machado, sindicalista, e com as pesquisadoras Verônica Clemente Ferreira, da UNICAMP e Ana Paula Alves de Oliveira, da Federação Estadual dos Metalúrgicos da CUT/SP, a quem agradecemos a colaboração.

Economic restructuring and health in the metal sector: the female workers' perceptions

Abstract: This paper discusses the new gender division of labour which results from the restructuring process in the metal industry 
emphasizing its impacts on the work and health conditions of women workers. The qualitative research conducted in plants of different sizes in the ABC and Campinas (both in the State of São Paulo) focused on the new forms of female work as a result of the introduction of new management practices and new technologies. It also examines the perceptions of those women workers about the changes in their work and health conditions, with the purpose of understanding the relationship between the new forms of work process organization and the deepening of psychophysical suffering at work. We concluded that metal companies' restructuration has a clear gender bias as the places assigned to women in the new division of labor contribute to increase the deterioration of women work conditions. At the plants studied, female workers are more concentrated in low pay jobs, under bad work conditions without protection against the hazards derived from work activities. The paper shows that there is a clear relationship between the change in women's work conditions and the increasing of health problems and work diseases (such as RSI and stress among others).

Key-words: women workers, gender division of labour, restructuring process, metal industry, health conditions.

\section{Referências bibliográficas}

ABRAMO, L. Um olhar de gênero: visibilizando precarizações ao longo das cadeias produtivas. In: ABRAMO, L.; ABREU, A. R. P. (Orgs.). Gênero e trabalho na Sociologia latino-americana. São Paulo: ALAST, 1998.

ABREU, A. R. P. Mudança tecnológica e gênero no Brasil: primeiras reflexões. Novos Estudos Cebrap, São Paulo, n. 35, mar. 1993.

ALMEIDA, M. C. C. Características emocionais determinadas da LER. In: CODO, W.: ALMEIDA, M. C. LER: lesões por esforços repetitivos. Petrópolis: Vozes, 1995.

ARAÚJO, A. M. C.; AMORIM, E. R. A. Redes de subcontratação e trabalho a domicílio na indústria de confecção: um estudo na região de Campinas. Cadernos Pagu: Desafios da Eqüidade, Campinas, n. 17$18,2002$.

ARAÚJO, A.; CUNHA, A. M.; GITAHY, L.; RACHID, A. New management strategies and labour: a case study in the Brazilian white goods 
industry. Paper apresentado no XV World Congress of Sociology, Brisbane, Australia, 2002. (Mimeogr.).

ARAÚJO, A.; FERREIRA, V. C.; AMORIM, E. A. As novas modalidades do trabalho feminino em tempos de flexibilização e reestrututração produtiva. Trabalho apresentado no II International Congress Women, Work and Helth, Rio de Janeiro, 1999. (Mimeogr.).

ARAÚJO, A. M. C.; GITAY, L. Reestruturação produtiva e negociações coletivas entre os metalúrgicos paulistas. Idéias, v. 9, n.2, v. 10, n.1, p. 65-111, 2003.

BARRETO, M. Lesões por Esforços Repetitivos (LER): que danos causam no cotidiano das mulheres. In: OLIVEIRA, Eleonora Menicucci de; SCAVONE, Lucila (Orgs.). Trabalho, saúde e gênero na era da globalização. Goiânia: AB Editora, 1997.

. Violência, saúde e trabalho (uma jornada de humilhações). São Paulo: Educ/Fapesp, 2003.

BERLINGUER, G. Donna e salute. Roma: Il Pensiero Scientifico, 1978. p. 3-55.

BRANDIMILLER, P. A. Condições de trabalho nos bancos: fiscalizar ou negociar? In: O MUNDO do trabalho [clipping impresso da imprensa sindical]. São Paulo: Edição 46, Oboré, 1996.

CUNHA, M. A. de A. No brilho do verniz, a corrosão das operárias. Cadernos Pagu, Campinas, n. 10, 1998.

DIAS, E.; Mendes, R. Da medicina do trabalho à saúde do trabalhador. Revista de Saúde Pública, São Paulo, v. 25, n. 5, p. 341-346, 1991.

DEJOURS, C. A loucura do trabalho: estudo de psicopatologia do trabalho. São Paulo: Cortez, Oboré, 1988.

DELGADO, M. B. G. Terceirização e trabalho feminino. In: MARTINS, H. de S.; RAMALHO, J. R. (Orgs.). Terceirização: diversidade e negociação no mundo do trabalho. São Paulo: Hucitec, 1994.

DRUCK, M. G. Qualidade total e terceirização: o "taylorismo" dos anos 90 e suas implicações no mundo do trabalho. Revista Bahia Análise \& Dados, Salvador, v. 4, n. 2/3, p. 28-34, dez, 1994.

GITAY, L. Inovação tecnológica, subcontratação e mercado de trabalho. São Paulo em Perspectiva, n. 8, v. 1, p. 144-153, jan./mar. 1994.

FOUCAULT, M. Vigiar e punir. Rio de Janeiro, Vozes, 1993. 
HIRATA, H. Reestruturação produtiva e relações de gênero. Revista Latinoamericana de Estudos do Trabalho, v. 4, n.7, p. 11-12, 1998.

HIRIGOYEN, M. F. Assédio moral: a violênica perversa no cotidiano, Rio de Janeiro: Bertrand Brasil, 2001.

LEITE, M. P. A cadeia automotiva: da linha de montagem robotizada ao trabalho escravo. 1996. (Relatório Técnico de Pesquisa). Não publicado.

MESSING, K. Riscos para a saúde da mulher trabalhadora no local do trabalho. Québec, 1993. p. 9-13. Não publicado.

OLIVEIRA, E. M. de. A Psicopatologia sexualizada do trabalho: a reconstrução de um conceito. 1996. Tese (Livre Docência) Faculdade de Saúde Pública da USP.

de. Gênero, saúde e trabalho: um olhar transversal., In: OLIVEIRA, Eleonora Menicucci de; SCAVONE, Lucila (Orgs.). Trabalho, saúde e gênero na era da globalização. Goiânia, AB Editora, 1997.

A mulher, a sexualidade e o trabalho. São Paulo: Hucitec, 1999

. Corpos em processo de adoecimento na nova organização social do trabalho. Interseções Revista de Estudos Interdisciplinares, UERJ, Rio de Janeiro, v. 4, n. 2, p175-198, 2002.

OLIVEIRA, E. M. de; BARRETO, M. Engendrando gênero na compreensão das lesões por esforços repetitivos. Saúde e Sociedade, v. 6, n. 1, p. 77-99, jan.jjul. 1997.

OLIVEIRA, E.M. de; CARNEIRO, F;. STORTI, R. Gênero, saúde, trabalho: a dimensão oculta. São Paulo: Brasiliense, Sindicato dos Bancários de São Paulo, 1996. p. 15-30.

POSTHUMA, A. C.; LOMBARDI, M. R. Gênero e exclusão social no novo paradigma produtivo. Trabalho apresentado no XX Encontro Anual da Anpocs, GT Trabalho e Sociedade, Caxambu, 1996.

PERREAULT, M. A diferença sexual no trabalho: condições de trabalho diferentes ou uma questão de sexo? In: TORRES, S. L. (Org.). $O$ indivíduo na organização; dimensões esquecidas. São Paulo, Atlas, 1993. v. 2, p. 236-252. 
RIZEK, C.; LEITE, M. P. Dimensões e representações do trabalho fabril feminino. Cadernos Pagu, Campinas, n. 10, 1998.

SCAVONE, L. Saúde e gênero: impactos na família das doenças profissionais causadas pelo uso do amianto. In: OLIVEIRA, E. M.; SCAVONE, L. (Org.). Trabalho, saúde e gênero na era da globalização. Goiânia: AB Editora, 2002. p. 39-40

SCOTT, J. História das mulheres. In: BURKE, P. (Org). A escrita da história: novas perspectivas. São Paulo: Editora UNESP, 1992. p. 63-69. 